\title{
Perturbación de fuentes contaminantes en la sostenibilidad de la Bahía de Sechura
}

Disruption of polluting sources in sustainability of the Bay of Sechura

Rodolfo Gianmarco Vargas Collantes', Eroncio Mendoza Nieto

\section{RESUMEN}

Objetivo: Identificar las zonas con mayor perturbación en la sostenibilidad del ecosistema acuático en la bahía de Sechura. Método: Monitoreo de agua en la superficie y fondo del mar $(5,10$ y 15 metros de profundidad) durante 12 meses. Los resultados promedios obtenidos de diferentes parámetros evaluados de siete zonas de monitoreo, se compararon empleando la prueba de Tukey y su vez se contrasto con el ECA para agua categoría 2 y 4 . Para una mejor dinámica de los resultados, se usó análisis espacial (interpolación por IDM) con el software Arcgis 10.4.1. Resultados: Evidencian que en la zona de Puerto Rico, existe una baja concentración de oxígeno disuelto $(2,81 \mathrm{mg} / \mathrm{L})$; mientras Parachique tiene la concentración de coliformes fecales más altas de la bahía (118,10 NMP/100 MI); temperatura más alta tiene Chuyillachi con un valor de $24,2^{\circ} \mathrm{C}$ en metales pesados (cadmio, plomo y mercurio), aceites, grasas e hidrocarburos están por debajo del ECA para agua C4. Conclusiones: Se identificaron las zonas de amortiguamiento con mayor perturbación para la sostenibilidad del ecosistema acuático a Parachique y Chiyillachi de toda la bahía de Sechura.

Palabras clave: Fuentes contaminantes, ecosistema acuático y sostenible.

\section{ABSTRACT}

Objective: To identify the areas with greater disturbance in the sustainability of the aquatic ecosystem in the Bay of Sechura. Methods: Monitoring of water on the surface and bottom of the Sea $(5,10$ and 15 meters deep) for 12 months. Results averages obtained from different evaluated parameters of seven zones of turn is contrast with the ECA water category 2 and 4, were compared using the Tukey test and monitoring. For best results dynamics, was used (interpolation by IDM) spatial analysis with the software Arcgis 10.4.1. Results: TShow that in the area of Puerto Rico, there is a low concentration of dissolved oxygen $(2.81 \mathrm{mg} / \mathrm{L})$; While Parachique has the concentration of high fecal coliforms from the Bay $(118,10 \mathrm{MPN} / 100 \mathrm{Ml})$; higher temperature has Chuyillachi with a value of 24.2 ${ }^{\circ} \mathrm{C}$ in heavy metals (cadmium, lead and mercury), oil, grease and oil are below the ECA water C4. Conclusions: The buffer zones were identified with greater disturbance to the sustainability of the aquatic ecosystem to Parachique and Chiyillachi of the Sechura Bay.

Keywords: Contaminant sources, water and sustainable ecosystem. 


\section{INTRODUCCIÓN}

Las estadísticas de producción convierten a la bahía de Sechura, Piura, en un importante productor de recursos marinos, que conlleva a ser una importante área costera (Ministerio de la Producción, 2015) con altos contenidos de nutrientes y elevada producción de fitoplancton, zooplancton e ictioplancton, por lo cual es centro principal de actividad pesquera consistente de la acuicultura de conchas de abanico, generando una cadena productiva (concesiones, embarcaciones de fosfatos, desembarcaderos, vehículos de transporte plantas de proceso primario e industrial) importante, destinada principalmente para la exportación.

La causa más transcendente que genera impactos ambientales en la bahía de Chancay es la mala gestión de aguas servida para los efluentes de las actividades urbano domesticas sin tratamiento alguno (Cabrera, 2002). Se observa que en la bahía del Callao el ambiente marino contiene una importante carga orgánica y microbiana de coliformes fecales con 104 MP/100 mL que impactaron en las zonas adyacentes por acción de las corrientes (IMARPE, 2000),

Sin embargo, la bahía de Sechura se encuentra en considerable deterioro ambiental por causa de los embarcaderos de fosfatos que son una fuente principal de metales pesados en la zona de Puerto Rico (Hurtado, 2011), el terminal del oleoducto y los centros poblados ribereños, cuyos efluentes líquidos y aguas servidas son las principales fuentes contaminantes (IMARPE, 2007), de igual manera la Autoridad Nacional del Agua (2013) sostiene que los problemas de vertimiento de aguas residuales cuentan con un reducido número de plantas de tratamiento, y a su vez muchas se encuentran en estado inoperativo (ANA, 2012). Estudios realizados, demuestran que las variaciones de concentración de oxígeno disuelto en el fondo del mar es relativamente bajo (ESCAES, 2012), esto indica que la ausencia de oxígeno en el agua puede indicar la contaminación elevada por condiciones sépticas de materia orgánica o una actividad bacteriana intensa. Los resultados obtenidos por el Organismo de Evaluación y Fiscalización Ambiental muestra que los coliformes fecales tienen gran presencia en el cuerpo acuático (OEFA, 2015), sobrepasando los rangos establecidos por el ECA agua (MINAM, 2015). Esto obliga, aplicar recomendaciones técnicas a los involucrados para la recuperación y conservación del ecosistema marino, tomando acciones que reduzcan las fuentes contaminantes que conlleva a minimizar los impactos ambientales generadas por estas (MINAM, 2009), dando prioridad al ecosistema marino para un mejor aprovechamiento de los moluscos bivalvos, ya que es importante desde el punto de vista económico, social y ambiental.

La prohibición de la Unión Europea a las exportaciones de ciertos moluscos bivalvos durante más de cinco años viene originando grave pérdida económica y social afectando las cadenas de producción local. Actualmente existe restricciones a la exportación de ciertos moluscos bivalvos vivos, entre las cuales las especies de: palabritas (Donax spp.), concha navaja (Ensis macha) y almeja (Transenella panossa), entre otras. La Unión Europea exige ciertos parámetros en el entorno marino que deben cumplirse para la exportación de moluscos bivalvos.

Frente al problema de contaminación y el deterioro del ecosistema marino costero en la bahía de Sechura, se realizó el presente trabajo con el objetivo de: Identificar las zonas con mayor perturbación en la sostenibilidad del ecosistema acuático en la bahía de Sechura.

\section{MATERIALY METODOS}

El estudio fue realizado en la zona de amortiguamiento de la bahía de Sechura que comprende al frente de siete (7) localidades (Puerto Rico, Parachique, San Pedro, Chuyillachi, Matacaballo, Constante y Las Delicias), donde está situada al noroeste del Perú, región Piura, que comprende 109,610 $\mathrm{km}^{2}$, delimitada al norte por Punta Gobernador y PuntaAguja por el sur.

Se obtuvo los registros con 21 puntos de monitoreo (Figura 1). Para agua de mar en la superficie y fondo $(5,10$ y 15 metros de profundidad) por el periodo de 12 meses, los parámetros registrados fueron: temperatura $\left({ }^{\circ} \mathrm{C}\right)$, oxígeno disuelto $\left(\mathrm{O}_{2}\right)$, potencial de hidrogeno $(\mathrm{pH})$, coliformes fecales (NMP/100 $\mathrm{mL}$ ), mercurio ( $\mathrm{mg} / \mathrm{L})$, cadmio (mg/L), plomo $(\mathrm{mg} / \mathrm{L})$, aceites y grasas $(\mathrm{mg} / \mathrm{L})$, hidrocarburos $(\mathrm{mg} / \mathrm{L})$, fenoles $(\mathrm{mg} / \mathrm{L})$ y cromo hexavalente (mg/L), los cuales fueron procesados por las estaciones de monitoreo que comprenden cada 
centro poblado siendo estas: San Pedro (ERS26-SP, ERS-25-SP), Chuyillachi (ERS-24-CH, ERS-23-CH), Matacaballo (ERS-21-MA, ERS20-MA), Constante (ERS-19-CO, ERS-18-CO), Las Delicias (ERS-17-LD, ERS-16-LD, ERS15-LD, ERS-14-LD, ERS-12-LD), Parachique (ERS-11-PA, ERS-09-PA, ERS-E-PA, ERS-OPA), y Puerto Rico (ERS-06-PR, ERS-04-PR, ERS-03-PR, ERS-02-PR), posteriormente fueron comparados con el ECA para agua (MINAM, 2015) y calidad exigida a las aguas para cría de moluscos (UE, 2006), zona de amortiguamiento; donde se aplicó las pruebas de Tukey al nivel de $\alpha=0,05$. Para una mejor dinámica de los resultados, se usó el análisis espacial (interpolación por IDM) con el software Arcgis 10.4.1.

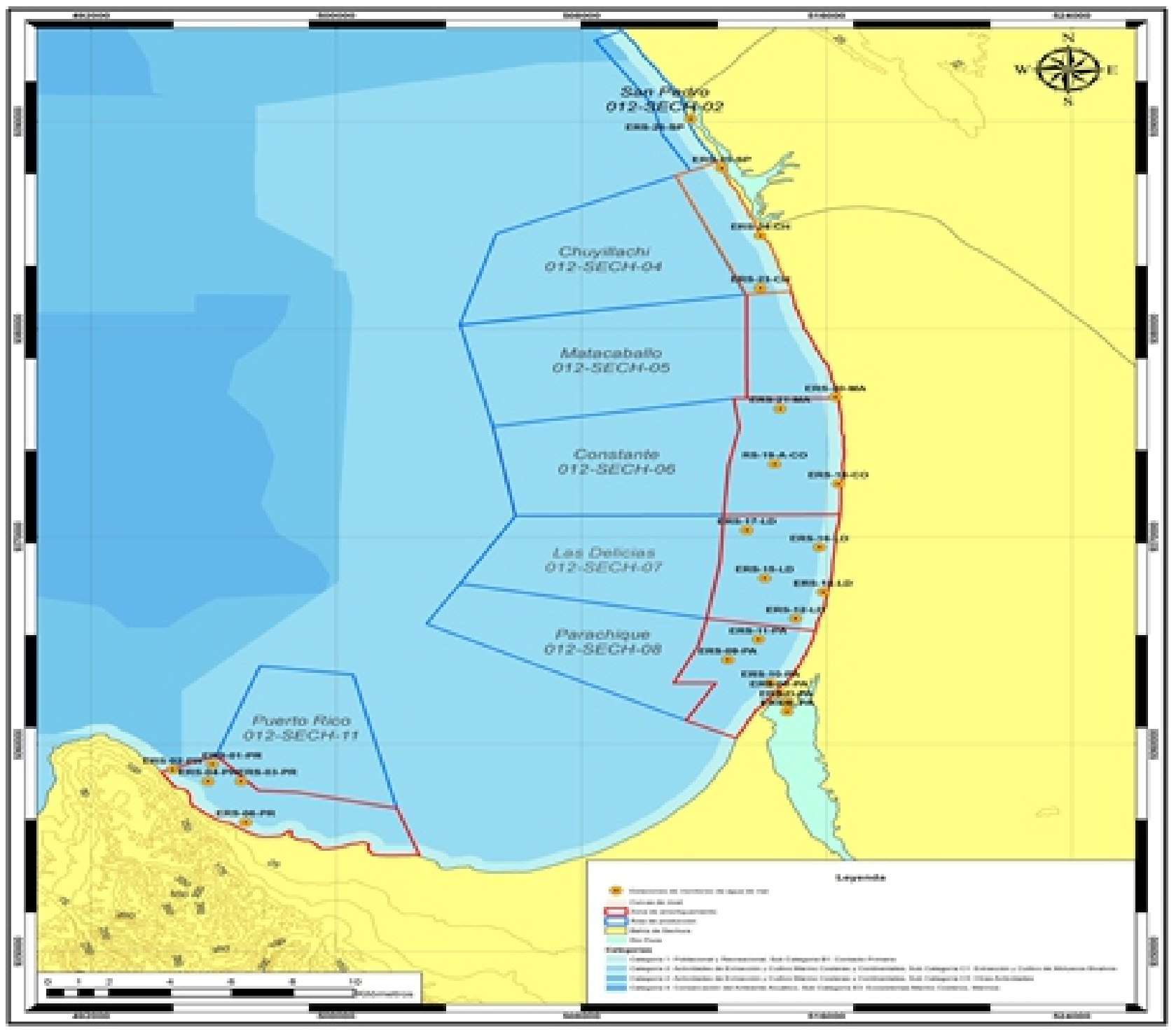

Figura 1. Ubicación geográfica de la bahía de Sechura y puntos de monitoreo

\section{RESULTADOS}

Los resultados obtenidos durante el monitoreo de agua de mar en la zona de amortiguamiento de la bahía de Sechura fueron los siguientes: Los análisis de laboratorio dieron indican que variaron en concentraciones de coliformes fecales, la zona de amortiguamiento de Parachique, presenta el máximo valor al tener de $118,10 \mathrm{NMP} / 100 \mathrm{ml}$, seguido por Chuyillachi con 68,50 NMP/100 ml, San Pedro con 32,60 NMP/100 ml y Puerto Rico con 14,93 NMP/100 $\mathrm{ml}$ como se muestra en la Figura 2. 


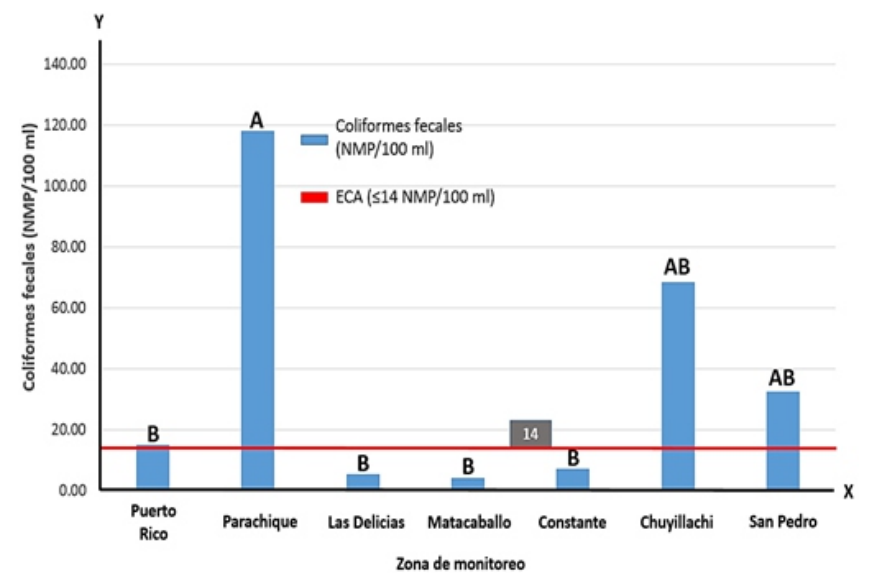

Figura 2. Variación de contenido de coliformes fecales en el agua del mar en diferentes zonas de monitoreo en la bahía de Sechura

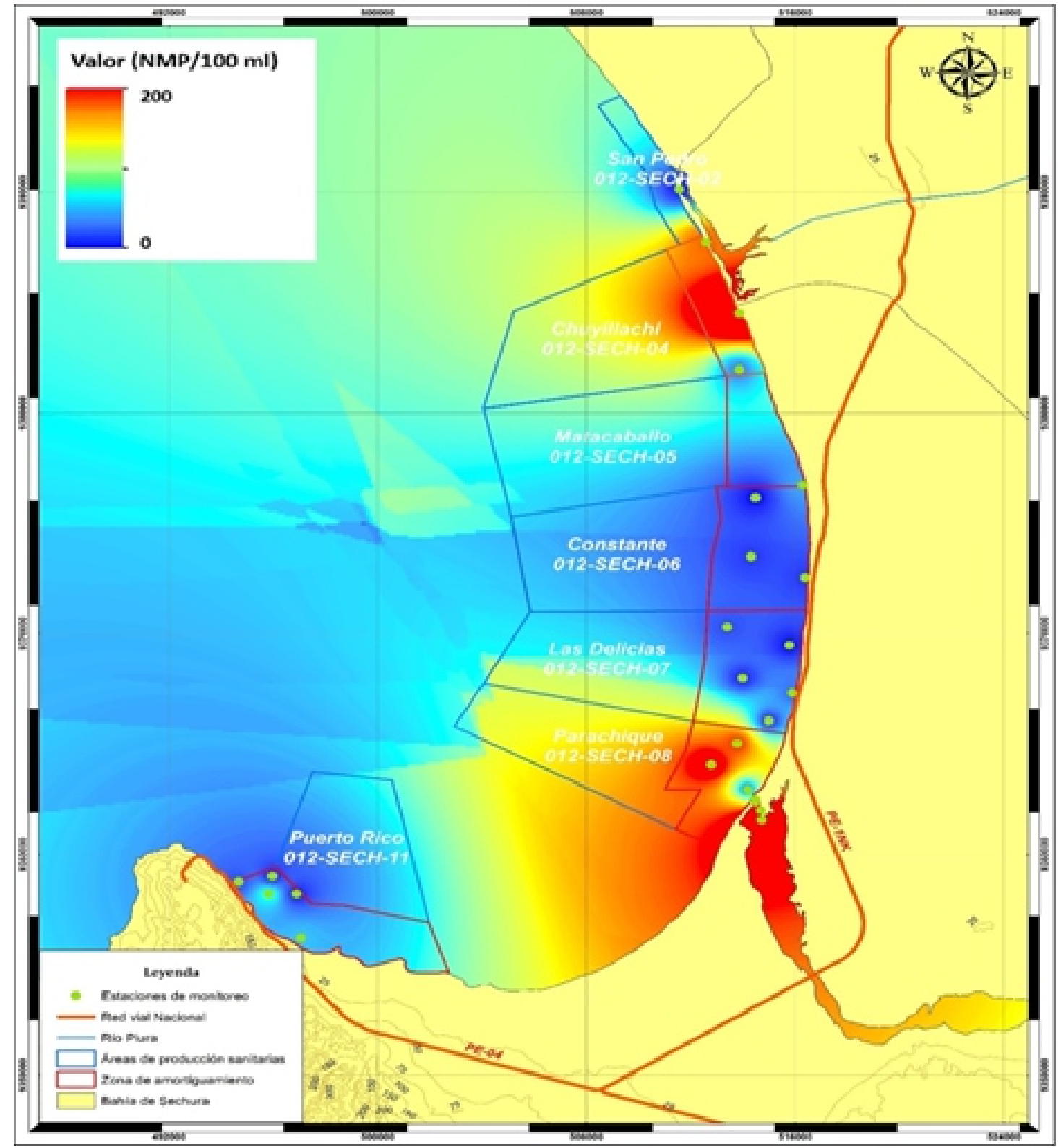

Figura 3. Resultados de los monitoreos de coliformes fecales (NMP/100 mL) en agua superficial del mar en la bahía de Sechura obtenidos por interpolación ID 
En la Figura 3 demuestra los resultados registrados por los monitoreos de temperatura en agua superficial en la bahía de Sechura procesadas por interpolación IDM, donde el color rojo es el valor más alto $(170,12 \mathrm{NMP} / 100$ $\mathrm{ml})$, verde es el valor medio $(85,97 \mathrm{NMP} / 100$ $\mathrm{ml}$ ) y azul el valor más bajo (1,82 NMP/100 ml).

En la Figura 4, muestra el registro de variaciones de temperatura encontrándose en Chuyillachi el máximo pico con $24,2{ }^{\circ} \mathrm{C}$, excediendo así el ECA para calidad de agua categoría 4 y 2 (sub categoría C1) ( \pm 2 de la temperatura promedio anual) al igual que la calidad exigida a las aguas para cría de moluscos $( \pm 2$ de la temperatura del promedio anual), mientras que en las zonas deParachique registró $23,12{ }^{\circ} \mathrm{C}$ y San Pedro $23,23{ }^{\circ} \mathrm{C}$ teniendo una similitud en sus resultados, al igual que Constante, Matacaballo y Las Delicias que están dentro de la norma establecida.

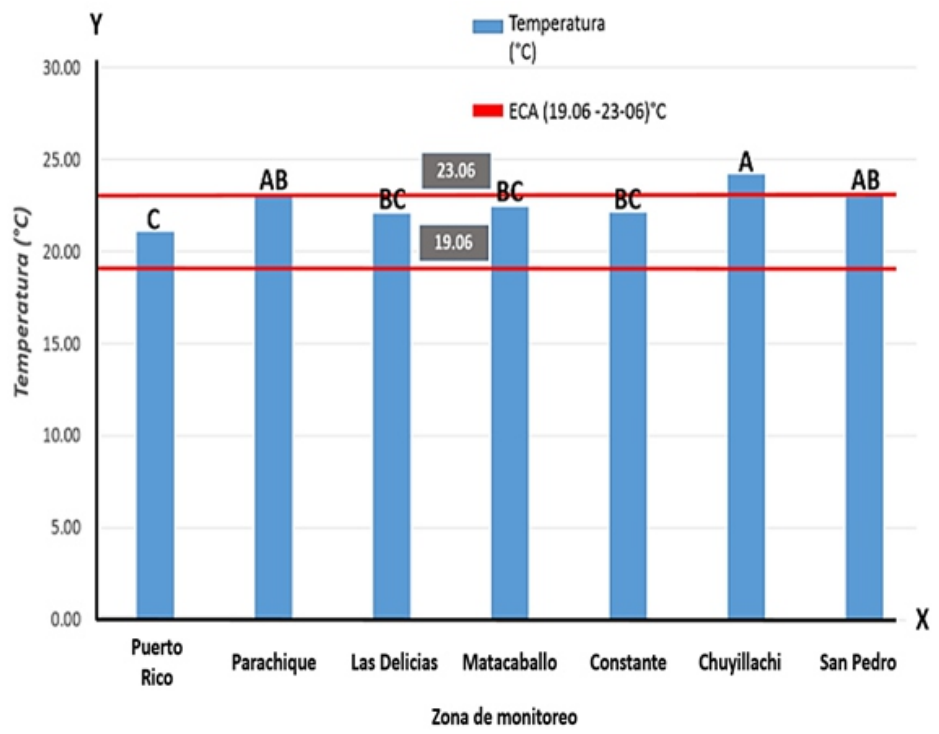

Figura 4. Variación de temperatura en agua superficial del mar en diferentes zonas de monitoreo de la bahía de Sechura

En la Figura 5 se muestra que la variación de temperatura en el fondo del mar done la zona de amortiguamiento de Parachique $(A)$ tiene la temperatura más alta $\left(21,72^{\circ} \mathrm{C}\right)$, estando estos en los rangos establecidos por el ECA para agua categoría 4 y 2 (sub categoría $\mathrm{C} 1$ ), del mismo modo a la calidad exigida a las aguas para cría de moluscos ( \pm 2 de la temperatura promedio anual) a la vez que en las zonas de Puerto Rico, Las Delicias, Matacaballo y Constante tienden a mantenerse dentro de la norma establecida $( \pm 2)$.

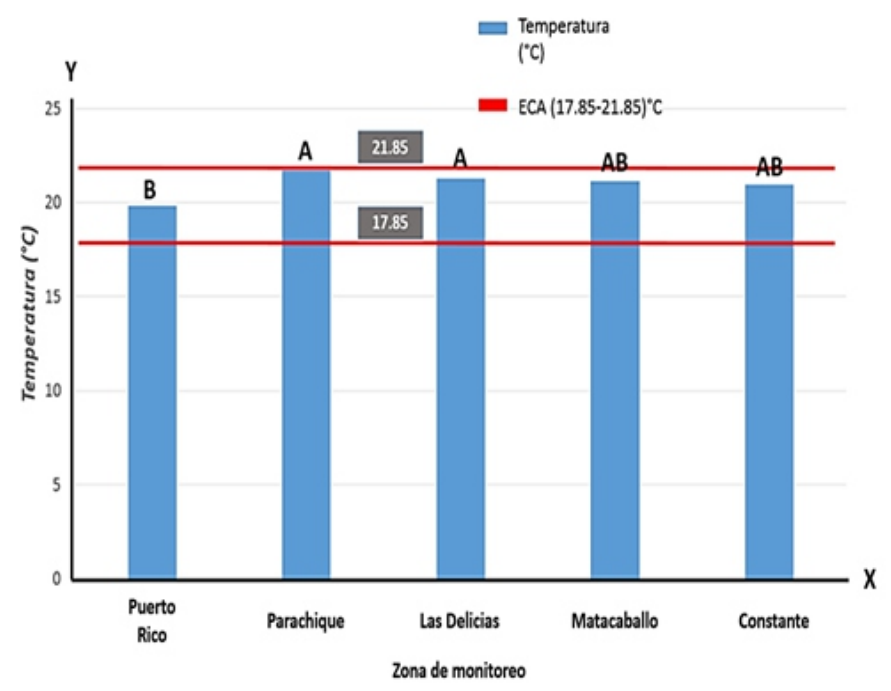

Figura 5. Variación de temperatura en agua de fondo del mar en diferentes zonas de monitoreo de la bahía de Sechura 


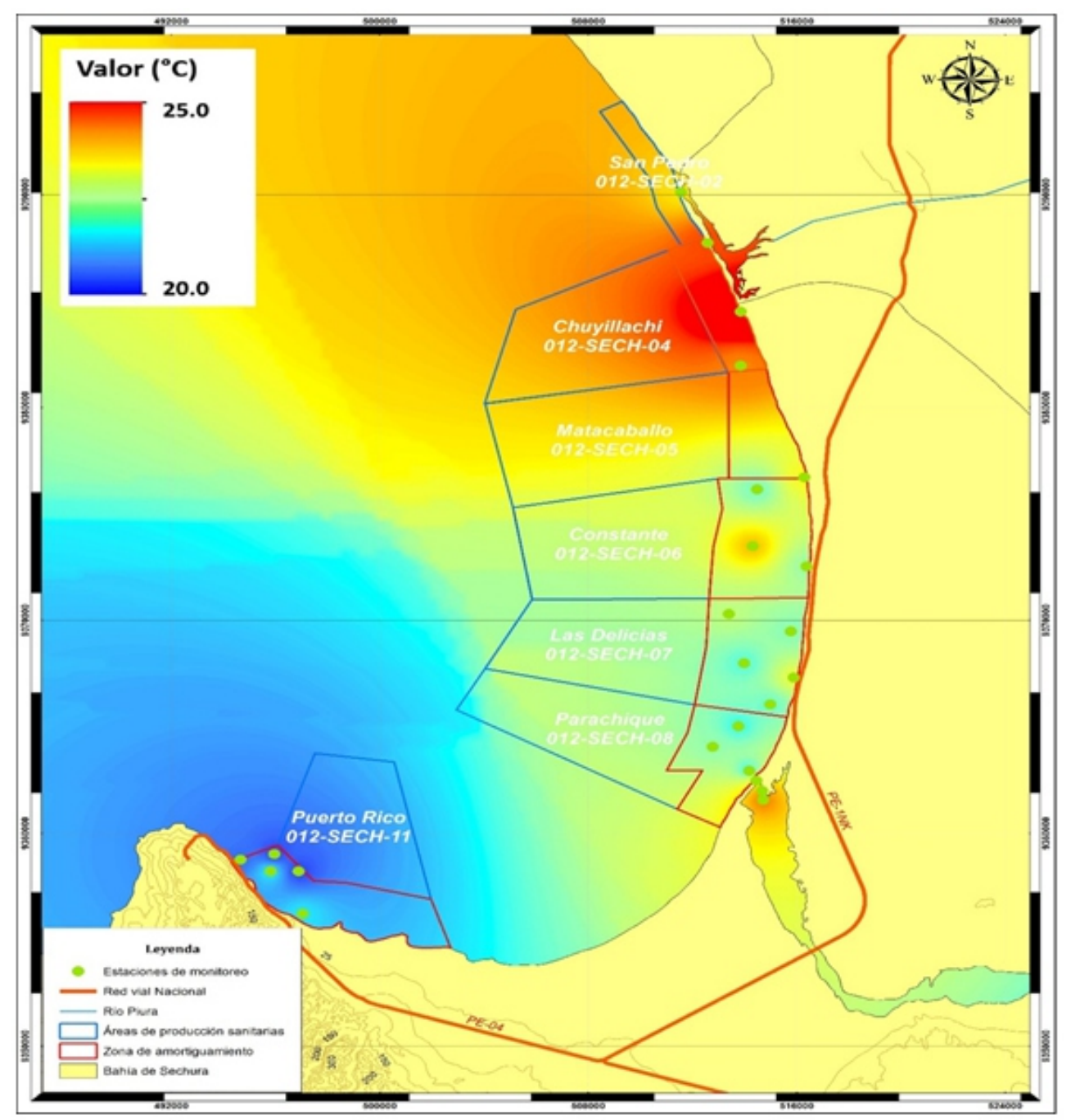

Figura 6. Resultados de los monitoreos de temperatura en agua superficial del mar de la bahía de Sechura obtenidos por interpolación IDM

\section{Potencial de hidrogeno $(\mathrm{pH})$}

En las Figuras 7 y 8 se muestran los resultados de la variación de potencial de hidrogeno $(\mathrm{pH})$ en la bahía de Sechura y tienden a ser asociadas $(A)$ estando dentro de lo establecido por el ECA para agua categoría 4 y 2 (sub categoría $\mathrm{C} 1$ ) y a la calidad exigida a las aguas para cría de moluscos $(7-9)$

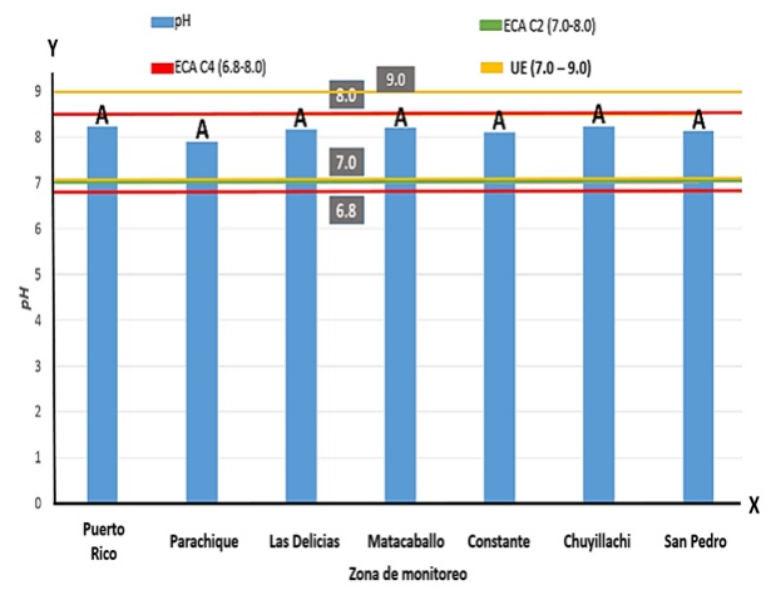

Figura 7. Variación del potencial de hidrogeno en agua superficial en diferentes zonas de monitoreos de la bahía de Sechura. 


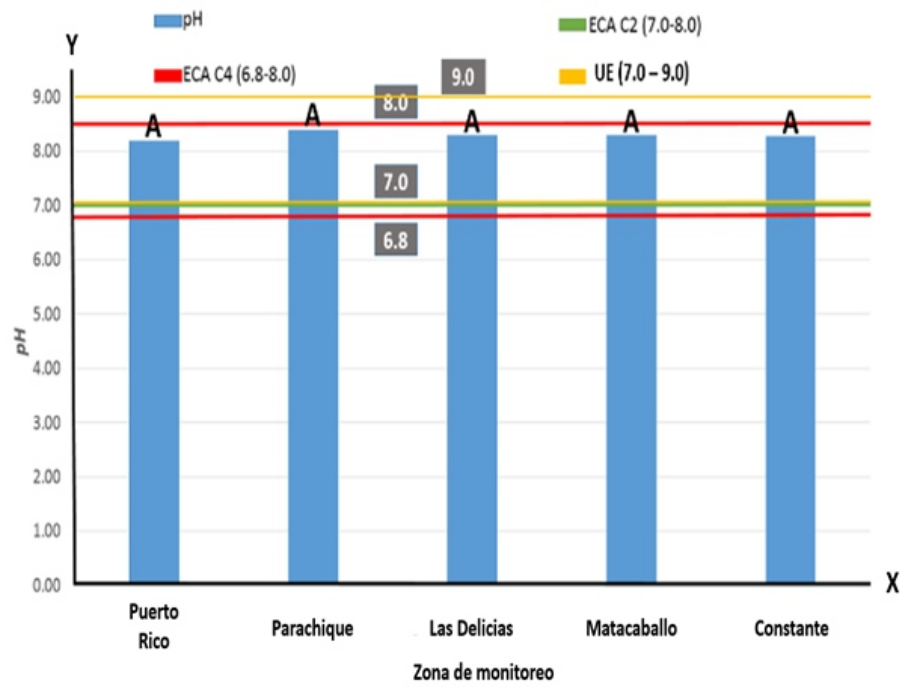

Figura 8. Variación del potencial de hidrogeno en agua superficial en diferentes zonas de monitoreo de la bahía de Sechura.

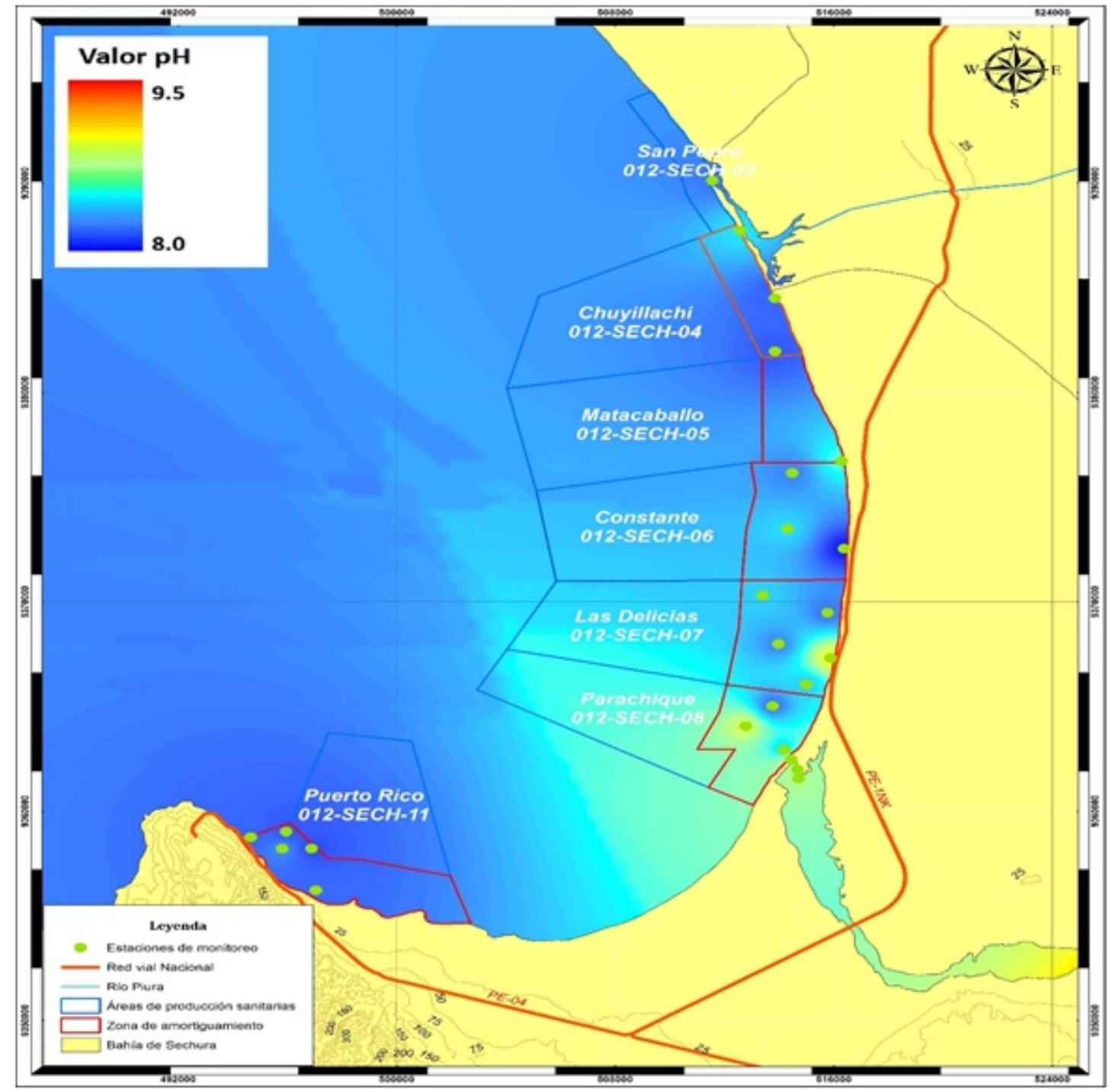

Figura 9. Resultados de los monitoreos de pH en agua superficial del mar de la bahía de Sechura obtenidos por interpolación IDM. 
En la Figura 9 afirma los resultados registrados de $\mathrm{pH}$ por los monitoreos en agua superficial en la bahía de Sechura procesadas por interpolación IDM, donde el color azul es el valor más bajo, verde es el valor medio y rojo el valor más alto.

En la Figura 10 las variaciones de oxígeno disuelto (mg/L) en los puntos de muestreo de la zona de amortiguamiento en la bahía de Sechura, donde se encontraron dentro de los rangos establecidos para el ECA para agua categoría 4 y 2 (sub categoría C1) teniendo la mayor solubilidad en Las Delicias con 6,94 $\mathrm{mg} / \mathrm{L}$ I a excepción de Parachique que tiene la menor solubilidad en la bahía $(3,57 \mathrm{mg} / \mathrm{L})$ estando por debaio del transepto del ECA.

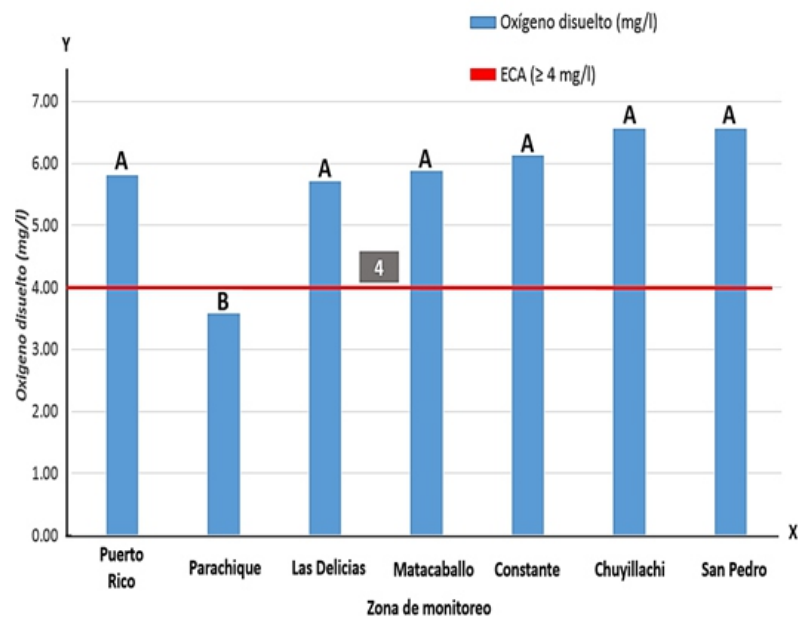

Figura 10. Variación del oxígeno disuelto en agua superficial del mar en diferentes zonas de monitoreo de la bahía de Sechura.
En la Figura 11 los resultados de la variación de oxígeno disuelto ( $\mathrm{mg} / \mathrm{L}$ ), indican que Puerto Rico tiene la menor solubilidad en la bahía de Sechura $(2,81 \mathrm{mg} / \mathrm{L})$ estando por debajo del ECA para calidad de agua categoría 4 ( $\geq \mathrm{mg} / \mathrm{L})$, teniendo asociación con los demás centros poblados.

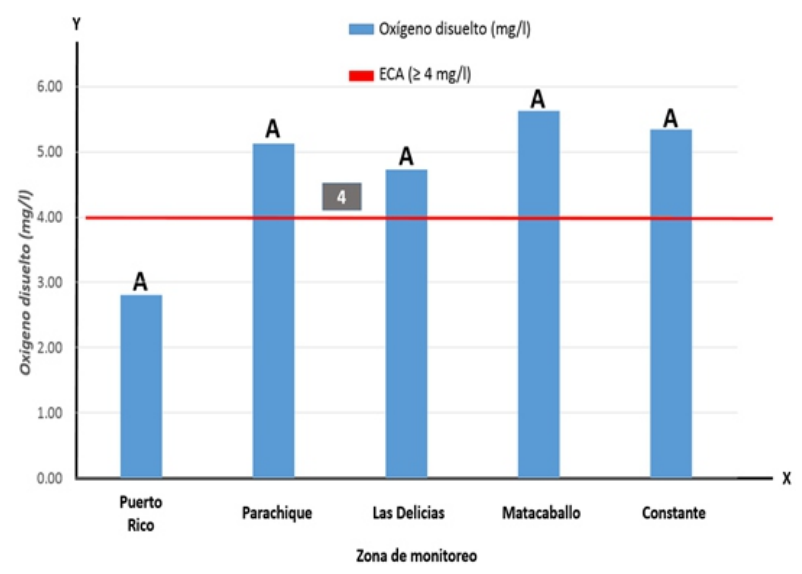

Figura 11. Variación del oxígeno disuelto en agua de fondo del mar en diferentes zonas de monitoreo de la bahía de Sechura

Los resultados de oxígeno disuelto obtenidos por los monitoreos en agua superficial fueron procesados por interpolación IDM como se muestran en la Figura 12, donde el color amarillo es el valor más bajo, verde medio y el azul el valor más alto

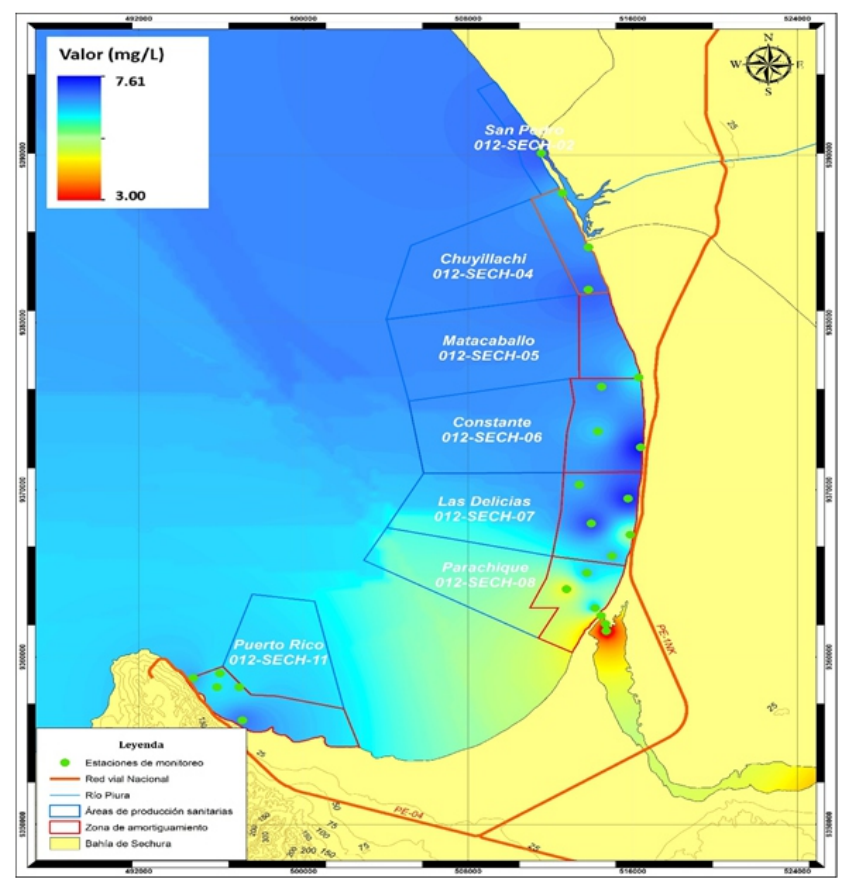

Figura 12. Resultados de los monitoreos de oxígeno disuelto en agua superficial del mar de la bahía de Sechura obtenidos por interpolación IDM. 
Los resultados de análisis de metales pesados (cadmio, mercurio y plomo), aceites, grasas, hidrocarburos y cromo hexavalente presentaron valores por el máximo valor cuantificable por los métodos utilizados por el laboratorio $(<0,0001)$ estando por debajo de los valores del ECA para agua categoría 2 (sub categoría C1) y categoría 4 de la calidad, y los límites de la calidad exigida a las aguas para cría de moluscos en hidrocarburos.

\section{DISCUSIÓN}

En la Figura 2 se observa que en la zona de amortiguamiento de Parachique tiene mayor concentración de coliformes fecales, esto se debería a causa de las aguas residuales domesticas e industriales que se vierten en el estuario de Virrilá, que es alimentada por el Rio Piura (brazo sur). De igual manera, en las orillas de San Pedro desemboca el Río Piura (norte), que es alimentada por vertimientos de aguas residuales domésticas e industriales de cuenca media, afirmando estos resultados con la evaluación ambiental en la bahía de Sechura donde se registró valores mayores a los encontrados (5100 NMP/100 mL) en San Pedro (OEFA, 2015). El contraste de los resultados entre el OEFA y los obtenidos se debe a que se promediaron en cada estación de monitoreo por centro poblado. El estudio de línea base del ámbito marino de la Bahía de Sechura (IMARPE, 2007) sostiene que las fuentes de contaminación corresponden a los centros poblados ribereños, y cuyos efluentes líquidos y aguas servidas son vertidos en su gran mayoría al litoral de la bahía de Sechura; al igual en el estudio de caracterización de aguas en la cuenca Piura (ANA, 2012) donde serían las plantas de tratamientos inoperativas en la zona. De esta manera los niveles encontrados muestran que existen problemas de contaminación en el ecosistema marino por vertimientos de aguas residuales, siendo este el habitad de desarrollo de la especies hidrobiológicas y principalmente de los moluscos bivalvos, llevando consigo a tener un habitad en deterioro y adecuado para el desarrollo de la producción (PRODUCE, 2015) afectando así la sostenibilidad en ella.

La temperatura $\left({ }^{\circ} \mathrm{C}\right)$ de Chuyillachi que tiene el valor más alto $(\mathrm{A})$ debido a los vertimientos calientes de plantas industriales, donde el alza de temperatura ocasiona una disminución de oxígeno disuelto, lo que causa alteraciones en el medio acuático. Los resultados de los monitoreos oceanográficos en la bahía de Sechura realizado por ESCAES (2012), demuestra que la temperatura máxima superficial del mar es de $26,4^{\circ} \mathrm{C}$, mientras que en el fondo fue de $23,7{ }^{\circ} \mathrm{C}$ indicando la presencia de aguas ecuatoriales superficiales, mientras que en la Figura 6 se muestra una temperatura máxima de $25,04^{\circ} \mathrm{C}$.

Los niveles de potencial de hidrogeno $(\mathrm{pH})$ comparados mediante la prueba de Tukey mostrados en las Figuras 7 y 8 se encuentran dentro los rangos de agua básica. En la Figura 9 muestra que en San Pedro se encuentran las aguas más básicas de la bahía.

En la Figura 10, Parachique muestra niveles de oxígeno disuelto por debajo del transepto del ECA de agua C4 (MINAM, 2015). Dicho parámetro es vital para la supervivencia de los organismos acuáticos que consumen oxígeno durante su degradación. Esto se debería a que las bacterias aerobias de las heces fecales que son vertidas al mar acaban dejando el agua sin oxígeno, creándose así una situación anóxica que puede producir la muerte de organismos acuáticos aerobios. En la Figura 11, se muestra que Puerto Rico $(A)$ tiene la menor solubilidad, lo cual confirma que los resultados de oxígeno disuelto en la zona de Bayóvar donde se registra una actividad antropogénica importante (OEFA, 2015). Esto se debería a las variaciones de concentración de oxígeno disuelto en el fondo fue relativamente bajo. Los niveles bajos o ausencia de oxígeno en el agua pueden indicar contaminación elevada, condiciones sépticas de materia orgánica o una actividad bacteriana intensa; por ello se puede considerar como un indicador de contaminación.

Los resultados de metales pesados (Cadmio, Plomo y Mercurio) están por debajo del ECA para agua $\mathrm{C} 4$. Este no sería una gran fuente de contaminación ambiental por los embarcaderos de roca fosfórica y el oleoducto norperuano (PETROPERÚ) para ecosistema. Los resultados del estudio de Bioacumulación de Cadmio y Plomo en concha de abanico a dos niveles de la columna de agua en la bahía de Sechura (Hurtado, 2011) afirma que existe presencia de metales pesados más no sobrepasan los niveles establecidos por la Unión Europea en estas especies. Se concluye que los metales pesados emitidos por la roca fosfórica en la bahía no presentan grandes problemas al ecosistema acuático y que la 
principal fuente contaminante es la desembocadura del Río Piura.

Las zonas de amortiguamiento con mayor perturbación en el ecosistema marino costero por las fuentes contaminantes serian Parachique y San Pedro

Se identificó que Parachique y Chuyillachi son las áreas de zona de amortiguamiento con mayor perturbación para la sostenibilidad del ecosistema acuático, asimismo las áreas de producción sanitarían de moluscos bivalvos tales como Parachique y Chuyillachi con protocolos sanitarios: (012-SECH-08) y (012SECH-04) se encuentran afectadas.

\section{AGRADECIMIENTO}

Al Organismo Nacional de Sanidad Pesquera (SANIPES) por haber brindado la información necesaria y oportunidad para ordenar, procesar y presentar esta investigación.

Asimismo, se reconoce al $\mathrm{Mg}$. Sc. Eroncio Mendoza Nieto por ser coautor del presente trabajo en su condición de asesor de tesis.

\section{REFERENCIAS BIBLIOGRÁFICAS}

Autoridad Nacional del Agua (2013). Plan de Gestión de los Recursos Hídricos de la Cuenca Chira-Piura, Informe Final, INCLAM.

Cabrera, C. (2002). Estudio de la contaminación de las aguas costeras en la Bahía de Chancay: propuesta de recuperación. Tesis para optar el grado de Magíster en Geografía no publicada. Universidad Nacional Mayor de San Marcos,Lima.

Escuela Campesina de Educación y Salud, ESCAES (2012). Informe "Monitoreo Bio-oceanográfico en las áreas de repoblamiento en la bahía de Sechura". Manos unidas, Sechura.

Hurtado, D. R. (2011). Bioacumulación de cadmio y plomo en concha de abanico (Argopecten purpuratus) a dos niveles de la columna de agua en la bahía de Sechura. Tesis de Ingeniero Pesquero no publicada. Universidad Nacional Agraria la Molina, Lima, Perú.

Instituto del Mar del Perú, IMARPE (2007). Estudio de línea base del ámbito marino de la Bahía de Sechura. Consultado 28 julio 2015 en

http://www2.produce.gob.pe/Repositori oAPS/3/jer/ACUISUBMENU4/Ibasesechura.pdf

Ministerio del Ambiente (2015, diciembre, 19). Decreto Supremo N 015-2015-MINAM. Modifican los Estándares Nacionales de Calidad Ambiental para Agua y establecen disposiciones complementarias para su aplicación. Diario Oficial El Peruano, 569076 569082.

Ministerio del Ambiente (2015, marzo, 25). Se inició el monitoreo participativo de la calidad ambiental en la Bahía De Sechura, Recuperado de http://www.minam.gob.pe/notas-deprensa/se-inicio-el-monitoreoparticipativo-de-la-calidad-ambientalen-la-bahia-de-sechura/

Ministerio de la Producción, PRODUCE (2015). Informe anual de producción pesquera y acuícola; frente al cambio climático y lineamientos de adaptación. Consultado el 19 agosto del 2015 en www.produce.gob.pe.

El Parlamento Europeo y El Consejo De La Unión Europea (2006, diciembre,12). Directiva 2006/113/CE del parlamento europeo y del consejo, relativa a la calidad exigida a las aguas para cría de moluscos, Diario Oficial de la Unión Europea, L 376/14 - L 376/20.

Correo electrónico: rodol882@gmail.com

Revisión de pares:

Recibido: 11-04-2017

Aceptado: 25-06-2017 